\title{
Erratum to: Estimated Healthcare Costs of Melanoma in Australia Over 3 Years Post-Diagnosis
}

\author{
Thomas M. Elliott ${ }^{1,2,3}$ - David C. Whiteman ${ }^{1,3}$ - Catherine M. Olsen ${ }^{1,4}$. \\ Louisa G. Gordon ${ }^{1,3,4,5}$
}

Published online: 12 September 2017

(c) Springer International Publishing AG 2017

\section{Erratum to: Appl Health Econ Health Policy DOI 10.1007/s40258-017-0341-y}

In the original publication, the 'Key points for decision makers' sentence which

previously read

Our extrapolated national estimates indicate that health system costs for melanoma have increased from AU $\$ 30$ million for 8885 new cases in 2001 to AU\$201 million for $\sim 13,000$ new cases in 2014.

should read

Our extrapolated national estimates indicate that health system costs for melanoma have increased from AU $\$ 30$ million for 8885 new cases in 2001 to AU\$201 million for $\sim 13,000$ new cases in 2017.

The online version of the original article can be found under doi:10. 1007/s40258-017-0341-y.

Louisa G. Gordon

louisa.gordon@qimrberghofer.edu.au

1 Population Health Department, QIMR Berghofer Medical Research Institute, Herston, Brisbane Q4006, Australia

2 Menzies Health Institute Queensland, Centre for Applied Health Economics, Griffith University, Logan Campus, University Dr, Meadowbrook Q4131, Australia

3 Centre for Research Excellence in Sun and Health Queensland, University of Technology, Victoria Park Rd, Kelvin Grove, Brisbane Q4059, Australia

4 School of Public Health, The University of Queensland, Brisbane, Australia

5 School of Nursing, Queensland University of Technology, Brisbane, Australia
The last word in the first paragraph which previously read AU\$25 million should read 25 million as this relates to population size.

In Table 5, the row 'Number of cases' was incorrectly published due to miscalculation as the numbers are 10 times higher than the actual values.

The correct Table 5 is given here 
Table 5 Annual cost of melanoma by Australian state or territory (2017 AU\$)

\begin{tabular}{|c|c|c|c|c|c|c|c|c|}
\hline & NSW [34] & VIC [34] & QLD [34] & SA [34] & WA [34] & TAS [34] & ACT [34] & NT [34] \\
\hline Melanoma incidence (persons/100,000/year) & 79.2 & 63.6 & 110.9 & 59.3 & 77.0 & 82.3 & 73.9 & 65.7 \\
\hline Number of cases & 5782 & 3579 & 5063 & 982 & 1873 & 422 & 277 & 155 \\
\hline Melanoma costs $(\$ \text { million })^{\mathrm{a}}$ & 62.0 & 38.4 & 54.3 & 10.5 & 20.1 & 4.5 & 3.0 & 1.7 \\
\hline
\end{tabular}

Aggregating the costs across the states will not equal \$201 million from Table 3 because incidence figures from the state registries are not all from the same year. The most recent reported incidence figures were used

NSW New South Wales, VIC Victoria, QLD Queensland, SA South Australia, WA Western Australia, ACT Australian Capital Territory, NT Northern Territory

${ }^{\text {a }}$ Costs include a multiplier to account for in situ melanomas 